\title{
Aortic valve regurgitation and the congenitally bicuspid aortic valve: a clinico-pathological correlation
}

\author{
A S Sadee, A E Becker, H A Verheul, B Bouma, G Hoedemaker
}

Department of
Cardiology,
University of
Amsterdam,
Academic Medical
Center, Amsterdam,
The Netherlands
A S Sadee
H A Verheul
B Bouma
G Hoedemaker
Department of
Cardiovascular
Pathology, University
of Amsterdam,
Academic Medical
Centre, Amsterdam,
The Netherlands
A E Becker
Correspondence to:
Dr A Eecker, Department
of Cardiovascular Pathology,
Academic Medical Center,
Meiberdreef 9,1105 AZ
Amsterdam-Zuidoost, The
Netherlands.
Accepted for publication
12 September 1991

Department of

Cardiology,

Amsterdam

Academic Medical

Center, Amsterdam,

The Netherlands

Pathology, University

of Amsterdam,

Centre, Amsterdam

The Netherlands

A E Becker

Correspondence to: of Cardiovascular Pathology, Academic Medical Center Amsterdam-Zuidoost, The

Accepted for publication

\begin{abstract}
Objective-To investigate the morphology of congenitally bicuspid aortic valves causing pure valve regurgitation.

Design-A case series collected over five years.

Setting-An academic hospital.

Patients and methods-One hundred and forty eight excised congenitally bicuspid aortic valves. The morphological findings were correlated with sex, age, clinical history, and data on haemodynamic function before operation. Pure valve regurgitation was defined as grade 3-4/4 with a gradient less than 30 mm Hg. Aortic root dilatation was evaluated angiographically or echocardiographically or both.
\end{abstract}

Results-Three types were recognised: valves that were purely bicuspid (23\%), bicuspid valves with a raphe (34\%), and valves with an additional indentation of the free edge of the conjoined cusp (43\%). In 14 cases pure valve regurgitation was present. Dilatation of the aortic root was present in 47 cases. The relative risk for regurgitation when the aortic root was dilated (compared with no dilatation) was 3.99. The relative risk for valve regurgitation when there was indentation of the conjoined cusp (compared with no indentation) was 4.95 . The mean age at operation in patients with pure regurgitation was 56 years, which is significantly younger $(p=0.0008)$ than that of patients with a congenitally bicuspid valve with combined valve stenosis and regurgitation (64.7 years).

Conclusions-Congenitally bicuspid aortic valves with a central indentation of the free edge of the conjoined cusp seem particularly likely to develop pure aortic valve regurgitation.

Congenitally bicuspid aortic valves are not rare. The frequency of such valves in the population is estimated at approximately $1-2 \% .^{1}$ The clinical course is usually dominated by acquired conditions such as infectious endocarditis and degenerative changes. Degenerative changes are an important cause of aortic valve stenosis requiring valve replacement. ${ }^{2-4}$ Less is known, however, about the morphology of the congenitally bicuspid aortic valve that causes pure aortic valve regurgitation.
The present study was designed to investigate this particular aspect.

\section{Patients and methods}

We studied 148 patients (99 men, mean age $63.6(31 \cdot 3-85 \cdot 7) ; 49$ women, mean age 65.4 $(34.9-81.0)$ ) who had aortic valve replacement because they had what appeared to be a congenitally bicuspid valve. Patients with infectious endocarditis were excluded.

For each patient we noted the sex, age, clinical history, and haemodynamic variables assessed during preoperative cardiac catheterisation. Pure aortic valve regurgitation was defined as grade 3-4/4 with a gradient of less than $30 \mathrm{~mm} \mathrm{Hg}$ measured during cardiac catheterisation. $^{5}$ Aortic root dilatation was assessed preoperatively during catheterisation in the usual qualitative manner, ${ }^{6}$ or by means of $M$ mode echocardiographic examination of the aorta in the parasternal long axis $(>37 \mathrm{~mm}) .^{7}$

All 148 valves were fixed in $10 \%$ formaldehyde. Those valves excised in parts were carefully reconstructed. We paid particular attention to the shape of the leaflets and the presence or absence of a raphe. Calcifications, when present, were graded in a semiquantitative manner as slight $( \pm)$, moderate $(t)$ or severe $(+t)$. Calcifications were graded as slight if only a few calcified spots were identified. Valve calcification was regarded as severe when there were extensive deposits throughout both leaflets. Calcification between these extremes was graded as moderate.

\section{STATISTICAL ANALYSIS}

Differences between the recorded results where $p<0.05$ were regarded as statistically significant. Differences between proportional variables were tested with a $\chi^{2}$ test and differences between continuous variables were tested by Student's $t$ test. The study population was stratified according to valve morphology and the presence of aortic root dilatation. Risk ratios with $95 \%$ confidence intervals for aortic valve regurgitation were calculated according to Miettinen and Nurminen. ${ }^{8}$

\section{Results}

Three categories of valve morphology were identified (table 1 and figure). Firstly, valves with a raphe, which were classified as congenital bicuspid aortic valves with a conjoined cusp. There were 51 valves of this type (34\%). 

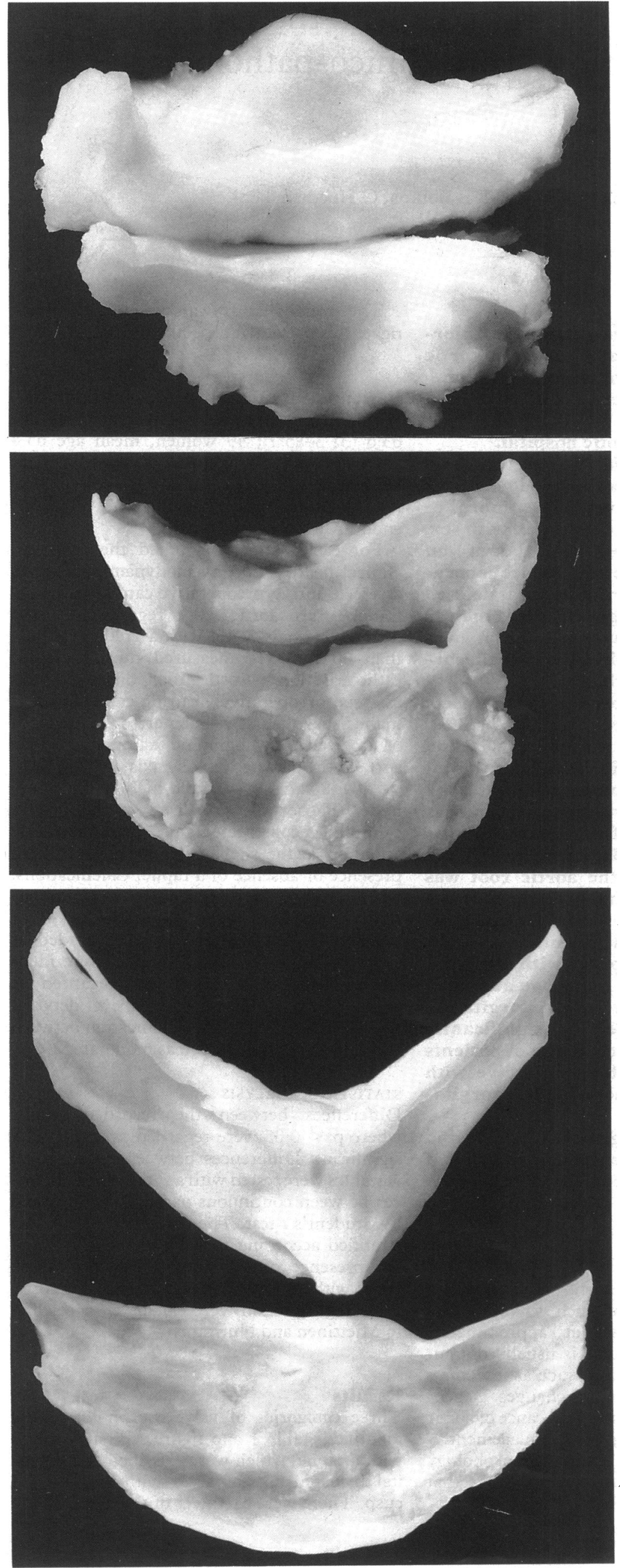

Secondly, a similar bicuspid valve with a distinct indentation of the free edge of the conjoined leaflet. There were 63 valves in this class $(43 \%)$. Finally, in 34 congenitally bicuspid valves there was no detectable raphe $(23 \%)$.

Of the 148 valves 143 showed some degree of calcification (table 1). The five valves without calcification all belonged to the group of (14) valves with pure regurgitation.

There was pure aortic valve regurgitation in 14 patients and dilatation of the aortic root in 47. Tables 1 and 2 show the correlation of valve dysfunction with each of the three different types of valve morphology and the relation between valve dysfunction and aortic root dilatation. Table 3 shows the data on valve morphology and the state of the aortic root in relation to the occurrence of pure aortic regurgitation.

We calculated the relative risk (RR) of pure aortic valve regurgitation when the aortic valve was indented. We also calculated the relative risk of valve regurgitation when the aortic root was dilated. Table 4 shows the results and the 95\% confidence intervals.

Patients with pure valve regurgitation were significantly younger (mean 56 years) at operation ( $p=0.0008$ ) than the group with congenitally bicuspid valves who did not have pure valve regurgitation (64.7 years). The numbers were too small to show any significant differences in age at operation in the subgroups.

\section{Discussion}

Examination of 148 surgically resected congenitally bicuspid aortic valves showed three distinct groups: purely bicuspid valves (23\%), bicuspid valves with a conjoined cusp containing a raphe $(34 \%)$, and valves with a conjoined cusp and a distinct central indentation of the free edge $(43 \%)$. This particular morphology has been reported as an important cause of isolated aortic regurgitation, ${ }^{910}$ but its importance has not been further evaluated.

The present study shows that this particular type of valve morphology is likely to underly pure aortic valve regurgitation. Indeed, this was the case in 11 of $63(17.5 \%)$ valves in this category, in contrast to only three $(3.5 \%)$ out of 85 valves without such an indentation. The underlying mechanism almost certainly relates to the fact that the peculiar morphology interferes with the proper coaptation of the valve cusps, particularly once degenerative age related changes make the valve leaflets less mobile.

The relative risk of valve regurgitation was significantly increased when a congenitally bicuspid valve was indented, (table 4 ).

Five of the 14 valves associated with pure valve regurgitation showed no gross calcifications, whereas there was slight to moderate

(Top) Gross appearance of a congenitally bicuspid aortic (Top) with degenerative changes; (middle) a congenitally valve with degenerative changes; (middle) a congen calcifications; and (bottom) a degeneratively changed congenitally bicuspid aortic valve with an indentation of the conjoined cusp, which also contains a raphe. The rolled free edge of the conjoined cusp is a clear expression of long term serious valve regurgitation. 
Table 1 Relation between valve dysfunction and valve morphology

\begin{tabular}{llll}
\hline Morphology & Pure regurgitation & Stenosis/regurgitation & Total \\
\hline Bicuspid & 1 & $33(7+; 26++)$ & 34 \\
Bicuspid with raphe & $2(1 \pm ; 1+)$ & $49(1 \pm ; 7+; 41++)$ & 51 \\
$\begin{array}{l}\text { Bicuspid with raphe and } \\
\text { indentation }\end{array}$ & $11(3 \pm ; 3+; 1++)$ & $52(14+; 38++)$ & 63 \\
\hline
\end{tabular}

Calcification: \pm , slight; + , moderate; ++ , severe.

Table 2 Relation between valve dysfunction and the state of the aortic root

\begin{tabular}{lllr}
\hline Root & $\begin{array}{l}\text { Pure } \\
\text { regurgitation }\end{array}$ & $\begin{array}{l}\text { Stenosis/ } \\
\text { regurgitation }\end{array}$ & Total \\
\hline Normal & 5 & 96 & 101 \\
Abnormal & 9 & 38 & 47 \\
\hline
\end{tabular}

calcification in the remaining nine valves. These observations contrast with the moderate to severe calcification in all valves associated with combined stenosis and insufficiency. The age at operation may be a factor but it is tempting to attribute this finding to haemodynamic differences.

Although prolapse of valve leaflets is widely accepted as a cause of regurgitation where the aortic valve is congenitally bicuspid, ${ }^{10}{ }^{11}$ none of our patients showed evidence of prolapse at the preoperative examination. On the other hand, dilatation of the aortic root is known to be an important associated anomaly..$^{9-11}$ Although the precise pathogenetic mechanisms are not yet fully understood, degenerative aortic medial disease is likely to be the underlying disorder. Whether this is congenital and part of a syndrome $e^{12}$ or a secondary effect caused by altered haemodynamic function affecting the ventriculoaortic junction remains to be established. In our study there was dilatation of the aortic root in $32 \%$ of the cases. The relative risk of aortic valve insufficiency was significantly higher when a congenitally bicuspid valve was

Table 3 Valve morphology and the state of the aortic root in relation to the occurrence of pure aortic regurgitation (total number of each type of valve is shown in parentheses)

\begin{tabular}{llllr}
\hline Aortic root & Bicuspid & Bicuspid/raphe & $\begin{array}{l}\text { Bicuspid/raphe/ } \\
\text { indentation }\end{array}$ & Total \\
\hline Normal & $0(21)$ & $0(37)$ & $5(43)$ & $5(101)$ \\
Abnormal & $1(13)$ & $2(14)$ & $6(20)$ & $9(47)$ \\
Total & $1(34)$ & $2(51)$ & $11(63)$ & $14(148)$ \\
\hline
\end{tabular}

Table 4 Relative risk of pure valve regurgitation

\begin{tabular}{lll}
\hline & No & $\begin{array}{l}\text { Relative risk } \\
\text { (95\% confidence interval) }\end{array}$ \\
\hline $\begin{array}{l}\text { Bicuspid/raphe/ } \\
\text { indentation }\end{array}$ & 63 & $4.95(1.6$ to 16$)$ \\
Abnormal aortic root & 46 & $3.99(1.5$ to 11$)$ \\
\hline
\end{tabular}

associated with aortic root dilatation (tables 2 and 4). Our results suggest that individuals with an abnormally wide aortic root and a bicuspid valve showing an indentation are more liable to develop pure valve regurgitation ( $30 \%$ of that subgroup). The numbers, however, are too small to regard these findings as more than highly suggestive.

The mean age at which valve replacement is performed in patients with a congenitally bicuspid aortic valve is significantly lower in those with pure valve regurgitation. In this study we identified aortic valves with an indentation of the conjoined cusp as an important cause of valve regurgitation-the clinical importance of this morphological type of valve is evident.

1 Edwards WD. Surgical pathology of the aortic valve. In: Waller BF, ed. Pathology of the heart and great vessels. New York: Churchill Livingston, 1980:43-100.

2 Subramanian R, Olson LJ, Edwards WD. Surgical pathology of pure aortic stenosis: a study of 374 cases. Mayo Clin Proc 1984:59:683-90.

3 Peterson MD, Roach RM, Edwards JE. Types of aortic stenosis in surgically removed valves. Arch Pathol Lab Med 1985;109:829-32.

4 Passik CS, Ackermann DM, Pluth JR, Edwards WD. Temporal changes in the causes of aortic stenosis: a surgical pathologic study of 646 cases. Mayo Clin Proc 1987;62:119-23.

5 Basta LL, Raines D, Najjar S, Kioschos JM. Clinical, haemodynamic, and coronary angiographic correlates of angina pectoris in patients with severe aortic valve disease. Br Heart J 1975;37:150-7.

6 Grossman W, Baim DS, eds. Cardiac catheterization, angiography and intervention. Philadelphia: Lea and Febiger, 1991:244-64.

7 Feigenbaum H, ed. Echocardiography. Philadelphia: Lea and Febiger, 1986:622.

8 Miettinen $\mathrm{O}$, Nurminen M. Comparative analysis of two rates. Stat Med 1985;4:213-26.

9 Guiney TE, Davies MJ, Parker DJ, Leech GJ, Leatham A The aetiology and course of isolated severe aortic regurgitation: a clinical, pathological, and echocardiographic study. Br Heart J 1987;58:358-68.

10 Davies MJ. Pathology of cardiac valves. London: Butterworths, 1980:37-61.

11 Olson LJ, Subramanian R, Edwards WD. Surgical pathology of pure aortic insufficiency: a study of 225 cases. Mayo Clin Proc 1984;59:835-41.

12 Lindsay J. Coarctation of the aorta, bicuspid aortic valves and abnormal ascending aortic wall. Am J Cardiol $1988 ; 61: 182-4$. 